\title{
Facial Nerve Schwannoma
}

\author{
G.S. Mankekar Junior Medical officer \\ A. G. Pusalkar Hony Associate Professor \\ C. A. Bhatt Hony. Associate Professor \\ AJBM ENT Hospital \& T.N. Medical College , Bombay.
}

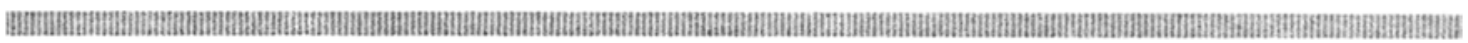

\section{Abstract}

An uncommon case of bilobed facial nerve schwannoma and its management is presented.

$\mathrm{F}$ condition and accounts for $5 \%$ of all cases of facial paralysis ${ }^{2,3}$. These tumours present variedly with otological symptmos, facial paralysis, a mass in the middle ear or a parotid mass. Symptoms are slowly progressive and diagnosis is often delayed. A high index of suspicion combined with modern imaging techniques is essential to diagnose this condition early so that facial nerve function can be preserved.

\section{Case Report}

A fifty-five year old hypertensive and diabetic lady presented to us with a history of giddiness, tinnitus, decreased hearing in left ear, left facial weakness and a swelling in the left retromandibular region. Past history revealed that patient had developed sudden-onset giddiness and tinnitus three years ago. She was treated with labyrinthine sedatives for six months and her symptoms decreased. A year later, left facial weakness was detected and was treated with steroids and infra-red light. However, the facial weakness progressed over a period of twelve to eighteen months to complete facial paralysis. At this time the patient Ideveloped a swelling in the left

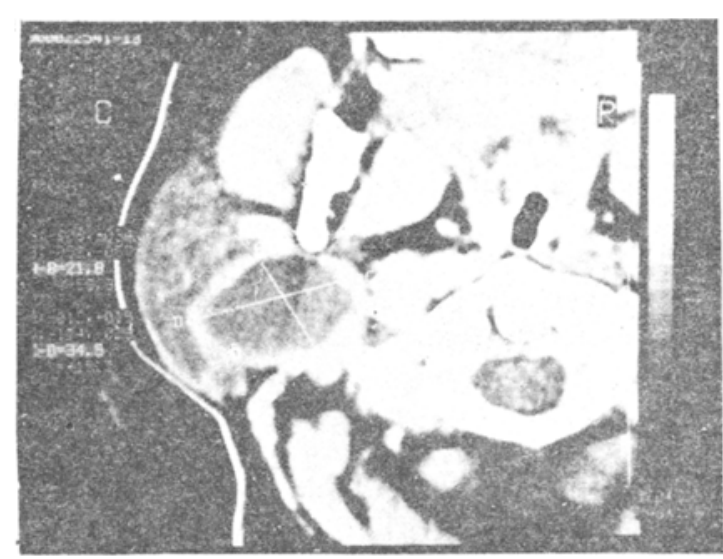

Fig 1: Axial CT left infralemporal region : cystic mass compressing parotid tissue.

retromandibular region and was referred to our outpatient department. On examination, she was noted to have left lower motor neuron type complete facial paralysis. On otoscopy, the left external auditory canal was narrowed by the bulging posterior canal wall. A $4 \times 4 \mathrm{~cm}$, Oval, firm, non-tender swelling was present in the left retromandibular region. Pure tone audiometry revealed a 40-50 decibel mixed hearing loss in the left ear with normal hearing in the right ear. Computed tomography 


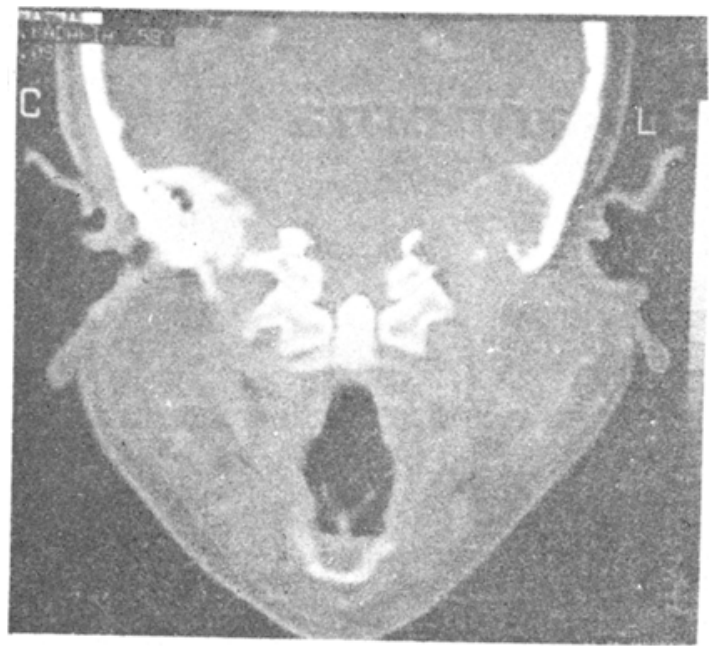

Fig 2: Coronal CT showing left temporal and infratemporal bilobed mass.

revealed a cyst in the left parapharyngeal region with a mass extending through the greater wing of sphenoid into the left mastoid antrum and posterior cranial fossa.

Under general anaesthesia, mastoidectomy with infratemporal fossa surgery was performed. The superficial parotid tissue was found to be compressed by a bilobed cystic swellins which extended upwards into the mastoid =. crum and internal auditory meatus.

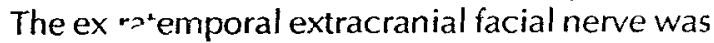
completely circumscribed by the tumour and could not be delineated separately from the tumour. The vertical facial nerve was also difficult to delineate separate from the tumour mass, while the horizontal facial was dehiscent but continuous. The tumour was removed extradurally and the external auditory canal was sutured. The wound was closed in layers leaving behind a suction drain. The patient had an uneventful recovery and has had no complications or recurrence for the past one year. Histopathology of the tumour revealed schwannoma.

\section{Discussion}

Facial nerve schwannomas account for less than $1 \%$ of intrapetrous tumours ${ }^{2}$ and for $5 \%$

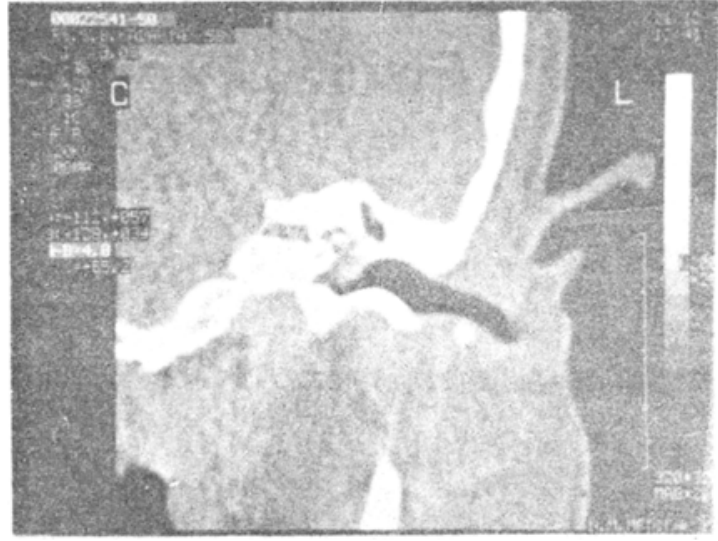

Fig 3: Coronal CT showing mass in left midelle ear and extending to internal auditory meatus.

of all cases of facial paralysis ${ }^{2,3}$. They can occur along the entire course of the facial nerve. The common sites of the schwannoma are geniculate ganglion, the horizontal segment of the facial nerve and the cerebellopontine angle. Schwannomas along the vertical segment of the facial nerve and bilobed schwannomas are rare'. Although facial nerve dysfunction is the commonest presenting symptom, facial nerve schwannomas may also present with hearing loss, vertigo and rarely otalgia '. Depending upon the presenting symptom, they may be mistaken for idiopathic facial palsy (Bell's), acoustic tumour, vertigo or even ulitis media or externa. Since the clinical presentition of facial nerve schwannomas is so subtle and insidious, a high index of suspicion is the mainstay of early diagnosis. Any incomplete facial paresis progressing to complete facial paresis progressing to complete facial dysfunction is not idiopathic in origin and any paralysis lasting for more than six months is not Bell's palsy. Therefore, any progressive or long-standing facial palsy needs to be investigated. Modern techniques of computed tomography and gadolinium enchanced magnetic resonance imaging enable early diagnosis of these tumours. 
The mainstay of treatment is surgical removal of the schwannoma followed by repair of the facial nerve with an interposition graft or facial hypoglossal anastomosis ${ }^{4}$. However, in the present case, inability to delineate infratem- poral and vertical facial nerve made it impossible to accomplish facial nerve reconstruction. An early diagnosis may have enabled either preservation or reconstruction of the facial nerve.

\title{
References
}

1. Altmann $F$ (1973) Seventh facial neurinoma in : Surgery of Facial Nerve. A. Miehlke (E) W. B. Saunders, Philadelphia, pp 98-108.

2. Daniels et al (1987) : facial nerve enhancement in magnetic resonance imaging. AJNR ; $8: 605-607$

3. Fisch $U$ and Ruthner J. 1977 : pathology of intratemporal tumours involving the facial nerve. In Facial nerve surgery; U. Fisch ( Ed) Kugler Publ. B. V. Amselveen, The Netherlands and Aesculapius

Publ.Co., Birmingham, AL, pp. 448-456.

4. Horn K.L. et al (1980) : facial neurilemmomas laryngoscope $91: 1326$ - 1331

5. Jackson E.G et al (1980) : facial paralysis of neoplastic orgin : diagnosis and management . laryngoscope 90:1581-1595.

\section{International Surgical Workshop on Middle Ear and Parotid and}

\author{
State of the Art Symposium (1st to 4th November 1998) \\ Organising Chairman : Professor A. pusalkar
}

LIVE SURGICAL DEMONSTRATION ON MIDDLE EAR AND PAROTID

Faculty: Professor J. Helms, Germany, Professor E. Steinbach, Germany, ProfessorH. Hildmann, Germany Professor A. Pusalkar, India

\section{State of the Art Symposium}

Topic

\section{Panel Discussions}

Malignant Neoplasams of Larynx-Management-Voice conservation

Hoarseness-Dilemas in diagnosis and management

State of Art approch to management of cholesteatoma

Management of Parotid-Facial Nerve Diseases

\section{Other Presentations}

latrogenic Facial Nerve Injury -management

Strategies in treatment of malignant parolid gland tumors

Reconstructive methods in repair of extratemporal facial nerve

Options and limits in modern imiging of parotid gland tumors

Surgical management of plcomorphic adenomas

Endonasal Sinus Surgery by the Microscope

Problems in Secondary Rhinoplasty

Endoscopic Surgery of the Middle Ear

Surgical anatomy of the larynx, parotid, facial nerve and nose

in relation to Rhinoplasty

3 Dimensional radio therapy of head and nock cancer

Voice rehabilitation after larynngectomy

Screening for hearing disorders in small children

Cholesteatoima with central perforation

Other eminent Otolaryngologists from India and abroad will participate.

For registration Demand draft of rs 3000/-drawn in favour of AJBM HOSPITAL SURGICAL WORKSHOP on any nationalised bank in Mumbai

Mailing address Organizing Secretary, 3rd International Surgical Workshop AJB Municipal ENT Hospital, 7 Maharshi Dandhichi Marg. Fort, Mumbai 400001
Fax No: 91-22-445 3802

\section{Moderator}

Prof J. Helms, Germany Dr. Jatin Mody

Professor A. Pusalkar

Prof. E. Stennert, Germany

Prof. J. Helms, Germany

Prof. E. Stennert, Germany

Prof. E. Stennert, Germany

Prof. E. stennert, Germany

Prof. E. Stennert, Germany

Prof. H. Hilfmann, Germany

Dr. W. Gubisch, Germany

Prof. T. S. karhuketo, Finland

Prof. Jan Pahnke, Germany

Dr. Leo Pfreundner, Germany Dr. Florian Hoppe, Germany Mrs. A. Hildmann, Germany Dr. Mazin-Al-Khabori, Muscat 